RAD Conference Proceedings, vol. 5, pp. 15-20, 2021

ISSN 2466-4626 (online) | DOI: 10.21175/RadProc.2021.03

www.rad-proceedings.org

\title{
DOES ALTITUDE HAVE AN EFFECT ON PIGMENT CONTENT OF WILD GROWING PLANTS IN RILA MOUNTAIN?
}

\author{
Tsveta Angelova ${ }^{*}$, Christo Angelov ${ }^{2}$ \\ Nikolai Tyutyundzhiev ${ }^{3}$, Svetla Gateva ${ }^{1}$, Gabriele Jovtchev ${ }^{1}$
}

\begin{abstract}
${ }^{1}$ Institute of Biodiversity and Ecosystem Research, Bulgarian Academy of Sciences, Sofia, Bulgaria
${ }^{2}$ BEO-Moussala, Institute for Nuclear Researches and Nuclear Energy, Bulgarian Academy of Sciences, Sofia, Bulgaria 3Central Laboratory of Solar Energy and New Energy Sources, Bulgarian Academy of Sciences, Sofia, Bulgaria
\end{abstract}

\begin{abstract}
Rila Mountain is the highest mountain on the Balkan Peninsula and is characterized with specific microclimate. It has been revealed that with the increase of the altitude, the differences in environmental conditions change at a great extent. In mountain conditions plants have to cope with combined environmental factors such as altitude, temperature, prolonged UV irradiation, and etc. The aim of this study is to assess whether pigment content in wild growing plant species is altitudes dependent. Five wild species, characteristic of the ecosystems in Rila Mountain: Fragaria vesca L. (Rosaceae), Myosotis sylvatica Ehrh. (Boraginaceae), Achillea millefolium L. (Asteraceae), Epilobium angustifolium L. (Onagraceae) and Dactylis glomerata L. (Poaceae) were used as plant material. Plants were collected from three different altitudes (Sofia-595 m; Rila Mountain-150o m a.s.l. and $1782 \mathrm{~m}$ a.s.l.) in July-August in growing season of 2020. Sofia was chosen as control altitude. Pigment content was applied as endpoint. Our data showed that the levels of total chlorophylls, chl. a, chl. $b$ and total carotenoids for plants growing at $1500 \mathrm{~m}$ a.s.l. were lower or similar to those measured at Sofia altitude for F. vesca, M. sylvatica, A. millefolium, E. angustifolium and D. glomerata L. There is no change in chlorophyll a/b ratio detected in plants at $1500 \mathrm{~m}$ a.s.l. altitude and $1782 \mathrm{~m}$ a.s.l. in the five investigated species. Based on our results it could be reveal the adaptation mechanism and survival strategies of F. vesca, $M$. sylvatica, A. millefolium, E. angustifolium and D. glomerata under complex environmental stresses in both mountain altitudes. On the other hand no change in the chlorophyll $a / b$ ratio could be an indication that altitudes have no permanent damage on the leaf photochemical system. It is known that chlorophyll content in plants is an indicator of their response to the habitat, weather, anthropogenic conditions. Because of the fact that in mountain conditions the effect of altitude is combined with other abiotic factors and that pigment content is very variable depending on many factors further studies using other plant species are needed for better understanding of the mechanisms of interaction between factors and plant response.
\end{abstract}

Key words: Mountain conditions, wild plant species, total chlorophylls, chlorophyll a, chlorophyll b, chlorophyll $a / b$ ratio, total carotenoids

\section{INTRODUCTION}

Rila Mountain is the highest mountain on the Balkan Peninsula and is located in the southwestern part of Bulgaria. Moussala Peak (2925 m above sea level, a.s.l.) is the highest peak of this mountain. As main hydrographic unit, Rila Mountain is situated on the border between temperate continental and continental Mediterranean climates and is characterized with a specific microclimate [1].

It is well known that mountains represent about $30 \%$ of the total land surface of the Earth [2]. With increasing altitude the environmental conditions change at a great extent. It has been observed that plant growth, morphology and physiology changed with the changing of the environmental conditions due to elevation.

With increase of the altitude plants are exposed to more extreme environmental conditions: increased UV intensity, low temperature, large diurnal fluctuations of temperature, high wind velocity, low partial pressures of $\mathrm{O}_{2}$ and $\mathrm{CO}_{2}$, limited water and nutrient supply and etc. The effect of all these factors is negative for plant growth and harmful to chlorophyll formation, plants morphological and physiological response [3], [4]. In altitudinal biology the major attention has been attracted by the main vital process for plantsphotosynthesis because of its dependence on temperature, light and partial pressure of $\mathrm{CO}_{2}$ and other environmental variables, which change with elevation [3], [4].

In mountains, low altitudes are generally better habitats for plant growth than high altitudes, which are related with decreasing in plant species diversity and abundance [4]. During the evolution plants have developed their own mechanisms to adapt to different environmental conditions such as adjust chlorophyll (Chl $a$, Chl $b$, Chl $(a+b)$, and Chl $a / b)$ and optimize photosynthesis [5]. Photosynthesis is the main vital process of green plants which is related with accumulation of organic matter and energy needed for

\footnotetext{
*angelova ts@abv.bg
} 
plant growth. The basic components of this process are photosynthetic pigments (chlorophylls and carotenoids) which absorb and transform solar energy. It is well known that photosynthetic pigments content is an indication of the response of plants to changes in environmental factors and the degree of adaptation to new environmental conditions [6]-[9]. The content of chlorophyll in plants is a species-specific or even variety-specific trait [10]. It may be an important indicator of the plant's life processes, which may affect the yield of biomass; also could be a reliable indicator of the: vitality of plants, their resistance to stressful (thermal and humidity conditions) [10] and their response to the habitat, weather and anthropogenic conditions [5], [10].

Considering the fact that the content of plant pigments is variable and depends on many factors, it was hypothesized that different plants species, growing at different altitudes would have different photosynthetic pigment content depending on the altitude. To check our hypothesis photosynthetic pigment content (total chlorophylls $(a+b)$, chlorophyll $a$, chlorophyll $b$, chlorophyll $a / b$ ratio and total carotenoids) was used as endpoint.

The most common types of chlorophylls occurring in nature are chlorophyll $a(\mathrm{Chl} a)$ and chlorophyll $b$ $(\mathrm{Chl} b$ ). Chlorophylls are typical for all photosynthetic organisms. Chlorophylls enable the conversion of light energy into the energy of chemical bonds. They determine the intensity of the plant color. Chl $a$ mainly absorbs red-orange light and $\mathrm{Chl} b$ absorbs blue-purple light, which suggest that the total amount of leaf chlorophyll content and allocated $\mathrm{Chl} a / b$ ratio directly influence the photosynthetic capacity of plants. The chlorophyll $a / b$ ratio in higher plants is about $3: 1$ [11] Carotenoids could be found in all photosynthetic organisms. As auxiliary pigments in photosynthesis, they transfer the absorbed energy to chlorophyll with an efficiency of $15 \%-90 \%$ and protect chlorophyll from excessive light intensity [10]. They also prevent destructive photo oxidation of organic compounds of protoplasm in the presence of free oxygen. Data in literature are unclear how leaf $\mathrm{Chl}$ content varies among plant species, plant functional groups, communities, especially at different altitudes. Certain factors might influence Chl levels, such as phylogeny, climate and soils [5]

The aim of this study is to assess whether pigment content in wild growing plant species is altitudes dependent.

\section{MATERIAL AND MethodS}

\subsection{Plant material}

Five wild growing species, characteristic of the ecosystems of Rila Mountain: Fragaria vesca L. (Rosaceae), Myosotis sylvatica Ehrh. (Boraginaceae), Achillea millefolium L. (Asteraceae), Epilobium angustifolium L. (Onagraceae) and Dactylis glomerata L. (Poaceae) were chosen as plant material. These plants are present at all three altitudes selected for our study. All plants were at same phenological stage. Samples were performed on fully expanded leaves in mature plants at flowering growth stage.

Plant samples of all five wild species were taken for research in growing season of 2020 on July-August. Three following collections of the species were made at each location.

Plant material for biochemical investigations was collected in moisture paper and after cooling at $4^{\circ} \mathrm{C}$ was taken to the laboratory. Then the plant material was stored at $-77^{\circ} \mathrm{C}$ immediately after sampling to keep it fresh for further use.

\subsection{Experimental sites}

Plants were collected from three points of each experimental site at three different altitudes: Sofia- 595 $\mathrm{m}$ a.s.l.; "Skakavcite"-1500 $\mathrm{m}$ a.s.l. and "III window"$1782 \mathrm{~m}$ a.s.l.

First experimental site, Sofia ("Borisova gradina"; $595 \mathrm{~m}$ a.s.l.) was chosen as control altitude.

Second experimental site was in Rila Mountain, locality named "Skakavcite" above the village Beli Iskar (Bulgaria) at $1500 \mathrm{~m}$ a.s.l. $\left(42^{\circ} 12^{\prime} 08.52^{\prime \prime} \mathrm{N} ; 23^{\circ} 33^{\prime}\right.$ $\left.06.38^{\prime \prime} \mathrm{E}\right)$. The soil type at this experimental site is brown forest with low clay content and high content of organic matter with acidic $\mathrm{pH}$ ranging between 4.5 and 6.0 [12].

Third experimental site was also in Rila Mountain, in the region of the locality named "Third window" at $1782 \mathrm{~m}$ a.s.l. $\left(42^{\circ} 10^{\prime} 27.70^{\prime \prime} \mathrm{N}, 23^{\circ} 33^{\prime} 33.20^{\prime \prime} \mathrm{E}\right)$. This experimental site has dark mountain-forest soils with acidic $\mathrm{pH}$ ranging between 4.0 and 5.0 [12].

\subsection{Radiation conditions at experimental sites}

The available data for average daily value of UV irradiation (UVA and UVB) for both experimental sites in Rila Mountain are for period of tree following years 2017, 2018 and 2019. The results are presented as $\mathrm{Wh} / \mathrm{m}^{2}$. Information for these parameters was obtained from the SoDa database (provider: MINES ParisTech/Armines/Transvalor (France) (http://www.soda-pro.com) derived from broadband HelioClim-3 v5 Solar Irradiance (satellite data). Average daily values for five successive months (May, June, July, August and September) are calculated [13].

The available data for UVA and UVB radiation for control site-Sofia are daily values averaged monthly for June, July, August, $2020\left(\mathrm{Wh} / \mathrm{m}^{2}\right)$. These data were calculated from measurements and collected database (N. Tyutyundzhiev). The UV sensor system is located on IE building in BAN complex 2 - Tzarigradsko Shosse Blvd. 72, Sofia.

\subsection{Photosynthetic pigments}

Pigment content (total chlorophylls, chlorophyll $a$, chlorophyll $b$, total carotenoids) (mg/g FW) was determined in fresh leaves samples taken from three experimental sites spectrophotometricaly according to Arnon (1949) [14] with some modifications. Chlorophyll $a / b$ ratio was calculated. 


\subsection{Data statistical analysis}

Experiments were repeated at least three times. Data points in figures are mean values. Error bars represent standard errors of mean values. Where no error bars are evident, the errors were equal to or less than the symbols. One-way ANOVA with Tukey multiple comparison tests (GraphPad Prism 6.04 software, San Diego, USA) were performed to assess differences among samples from different altitudes.

\section{RESULTS}

\subsection{Radiation conditions at experimental sites}

In our previous three years study (from 2017 to 2019) it was found that the increase in the intensity of UV radiation with height is clearly visible [13]. Based on our previous data for UV parameters for period of 2017-2019 it could be suggested that change of UV irradiation for one year is insignificant (about 1\%). From Figure 1 which presents the values of UVA and UVB radiation at the three localities chosen in our study for the growth seasons 2019/2020 it can be seen a dependence of UV irradiation with altitude (with increase of altitude, increases UV irradiation). The lowest values of UV radiation (UVA and UVB) were detected at the control site, Sofia. It is well known that for every 100 meters in height the UV radiation increases by $1 \%$.

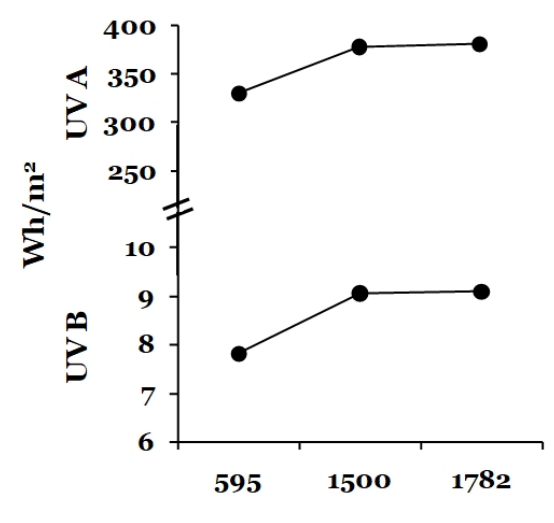

Altitude (m a.s.l.)

Figure 1. Values of UVA and UVB radiation detected at localities: Sofia city $595 \mathrm{~m}$ a.s.l.; Beli Iskar "Skakavcite" $1500 \mathrm{~m}$ a.s.l. and "Third window" $1782 \mathrm{~m}$ a.s.l. for the growth seasons 2019/2020.

In comparison to BG countryside at same altitude, the UVA and UVB values in Sofia city are $15-20 \%$ lower, due to air pollution of the capital from heavy car traffic in June, July, August. The increased concentration of PM10 hard aerosols and NOx emissions in the troposphere result in increased scattering of UVA and UVB light above the surface mainly at "rush" hours. At visible wavelengths these events are not detected.

According to our observations, the dependence from altitude looks like logarithmic not linear (N. Tyutyundzhiev).

\subsection{Total chlorophyll $(a+b)$ content}

Lower or similar levels of total $(a+b)$ chlorophylls for plants ( $F$. vesca, $M$. sylvatica, A. millefolium, $E$. angustifolium and D. glomerata) growing at $1500 \mathrm{~m}$ a.s.l and $1782 \mathrm{~m}$ a.s.l. were obtained compared with those at the control altitude (see Figure 2). Higher and statistically not significant levels of total chlorophylls ( $p>0.05$ ) were found for D. glomereta and F. vesca at $1782 \mathrm{~m}$ a.s.l. in comparison with those at $595 \mathrm{~m}$ a.s.l.

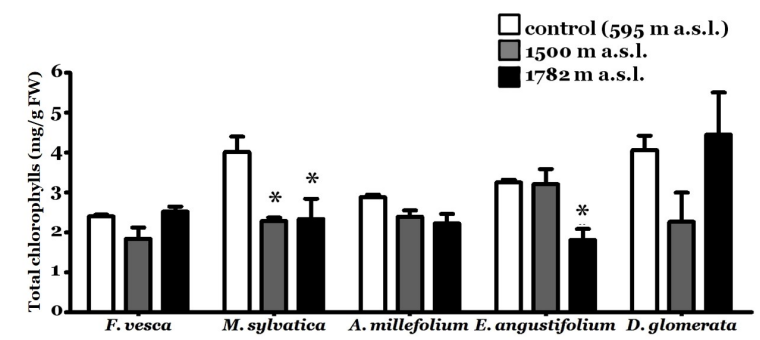

Figure 2. Total chlorophyll $(a+b)$ content $(\mathrm{mg} / \mathrm{g} \mathrm{FW})$. Statistically significant differences between the levels in plants at control altitude and those at higher altitudes $\left({ }^{*} \mathrm{p}<0.05\right)$.

\subsection{Chlorophyll $a$ and chlorophyll $b$ content}

Our data show that the levels of chlorophyll $a$ and chlorophyll $b$ for plants growing at $1500 \mathrm{~m}$ a.s.l and $1782 \mathrm{~m}$ a.s.l. were lower or similar to those measured at Sofia altitude for $F$. vesca, $M$. sylvatica, A. millefolium, $E$. angustifolium and D. glomerata (see Figure 3 ). Higher levels of chlorophyll $a$, but not statistically significant ( $\mathrm{p}>0.05$ ) were found for D. glomerata and $F$. vesca at $1782 \mathrm{~m}$ a.s.l. in comparison with those at $595 \mathrm{~m}$ a.s.1.

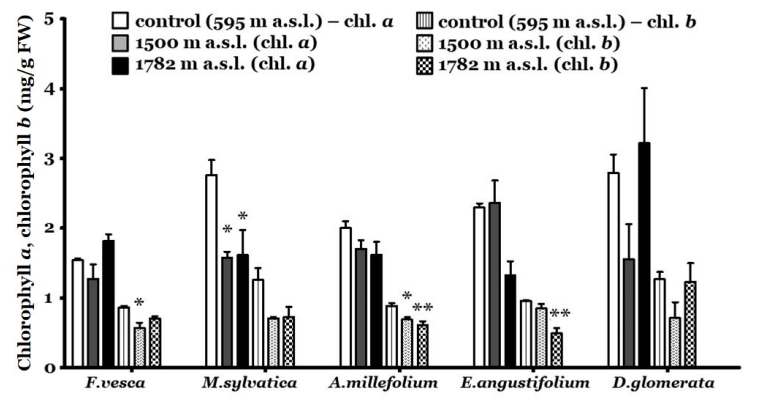

Figure 3. Chlorophyll $a$ and chlorophyll $b$ content (mg/g FW). Statistically significant differences between levels in plants at control altitude and at higher altitudes $\left({ }^{*} \mathrm{p}<0.05,{ }^{* *} \mathrm{p}<0.01\right)$.

\subsection{Chlorophyll $a / b$ ratio}

Table 1. Chlorophyll $a / b$ ratio in wild plant species growing at different altitudes, presented as Mean value \pm SEM

\begin{tabular}{|l|c|c|c|}
\hline \multirow{2}{*}{ genotype } & \multicolumn{3}{|c|}{ Chlorophyll $a / b$ ratio } \\
\cline { 2 - 4 } & $\begin{array}{c}\text { control } \\
(595 \text { m a.s.l.) }\end{array}$ & $\begin{array}{c}\text { Skakavcite } \\
1500 \text { m a.s.l. }\end{array}$ & $\begin{array}{c}\text { III Window } \\
11782 \text { m a.s.l. }\end{array}$ \\
\hline F. vesca L. & $1.782 \pm 0.019$ & $2.211 \pm 0.123$ & $2.579 \pm 0.043$ \\
M. sylvatica Elurh. & $2.218 \pm 0.136$ & $2.238 \pm 0.125$ & $2.201 \pm 0.075$ \\
A. millefolium L. & $2.271 \pm 0.219$ & $2.447 \pm 0.074$ & $2.635 \pm 0.155$ \\
E. angustifolium L. & $2.392 \pm 0.038$ & $2.765 \pm 0.194$ & $2.702 \pm 0.118$ \\
D. glomerata L. & $2.201 \pm 0.025$ & $2.168 \pm 0.043$ & $2.271 \pm 0.097$ \\
\hline
\end{tabular}


There is no change in chlorophyll $a / b$ ratio detected in five investigated plant species at $1500 \mathrm{~m}$ a.s.l. and $1782 \mathrm{~m}$ a.s.l. altitude (Table 1).

\subsection{Total carotenoid content}

Lower or similar levels of total carotenoids were measured for $F$. vesca, $M$. sylvatica, A. millefolium, $E$. angustifolium and D. glomerata growing at $1500 \mathrm{~m}$ a.s.l and $1782 \mathrm{~m}$ a.s.l. than those at Sofia (see Figure 4).

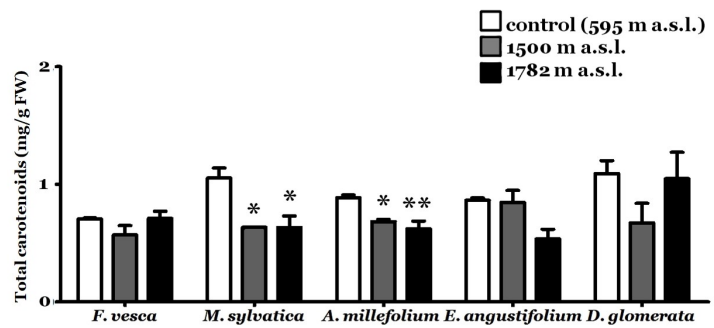

Figure 4. Total carotenoid content (mg/g FW). Statistically significant differences between levels in plants at control altitude and at higher altitudes $\left({ }^{*} \mathrm{p}<0.05,{ }^{* *} \mathrm{p}<0.01\right)$.

Statistically significant differences between the level in plants from control altitude and those from $1500 \mathrm{~m}$ a.s.l. and $1782 \mathrm{~m}$ a.s.l. were measured only for genotypes $M$. sylvatica and A. millefolium.

\section{DISCUSSION}

It is well known that in mountains with the increasing of the altitude oxygen pressure, precipitation and UV radiation intensity increase. UV irradiation increases with the elevations, especially the level of UV-B due to the thinner atmosphere. On the other hand, temperature and gravity are reduced. It could be suggested that the impact of altitude on plant growth is combined with the action of other abiotic factors. Photosynthetic pigments, which play a key role in main vital process in plants-photosynthesis are sensitive to environmental stresses and directly affect plant photosynthetic capacity. It is known that single action of UV irradiation could lead to damages of the plant photosynthetic apparatus. The effect of water stress, high light, high temperature could lead to reducing of chlorophyll content by slowing chlorophyll synthesis, accelerating decomposition or damaging chloroplast structures. The damage of photosynthetic apparatus is mainly in photosystem II of the light harvesting complex. Chlorophyll content could be an indicative trait for characterizing how plants respond to climate change, because of dependence of chlorophyll synthesis of water and soil [5].

Chlorophyll concentrations were inversely correlated with altitude [15], [16]. Our observations were made at different altitudes and with top leaves of herbaceous plants $F$. vesca, $M$. sylvatica, A. millefolium, E. angustifolium and D. glomerata. We obtained that total chlorophyll content measured in five herbaceous wild plants species, growing at both altitudes ( $1500 \mathrm{~m}$ a.s.l. and $1782 \mathrm{~m}$ a.s.l.) in Rila Mountain is lower or similar to that measured at control altitude (595 $\mathrm{m}$ a.s.l.), where the UV intensity is lower than that in Rila Mountain. However, genotype response, measured as total chlorophyll content varies depending on the species. Lower and statistically significant levels of total $(a+b)$ chlorophylls were obtained only for genotypes $M$. sylvatica (growing at both altitudes) and E. angustifolim (growing at $1782 \mathrm{~m}$ a.s.l.) in comparison with those at the control altitude. These results are in accordance with data of other authors [17]. The authors reported a decrease in total chlorophyll content in upper canopy leaves at the highest altitude (1100 $\mathrm{m}$ a.s.l.). The measurements were taken on leaves from upper and lower parts of the canopy of mature trees (>85 years old) growing at three different altitudes (400 $\mathrm{m}$ a.s.l., $720 \mathrm{~m}$ a.s.l., $1100 \mathrm{~m}$ a.s.l.), on the southern slope of the Hrubý Jeseník Mountains (Czech Republic). Difference in total chlorophyll content was obtained depending on the altitude and the leaf traits (lower or upper) in canopy trees. Other authors also found that chlorophyll content vary depending on the genotype (four Artemisia species), position of the leaves and altitude (550 $\mathrm{m}$ a.s.l. and $3600 \mathrm{~m}$ a.s.l. in Garhwal Himalaya) [16]. Reduced chlorophyll content is considered as one of the typical characteristic of the alpine plants.

In mountains the reduction of pigment contents (chlorophyll $a$ and chlorophyll $b$ ) with elevation is due to the combined effect of environmental changes and changes in altitudes.

Our data show that chlorophyll $a$ and chlorophyll $b$ contents measured at both altitudes $(1500 \mathrm{~m}$ a.s.l. and $1782 \mathrm{~m}$ a.s.l.) in five wild species, are lower or similar to those measured in plants at control altitude (595 $\mathrm{m}$ a.s.l.). Even though, some variability between wild species was detected in chlorophyll $a$ and chlorophyll $b$ contents. Only genotype $M$. sylvatica, growing at both altitudes had statistically lower levels of chlorophyll $a$ compared to those measured at control altitude while other genotypes were with similar levels to control. On the other hand statistically reduced levels of chlorophyll $b$ were measured for genotypes: A. millefolium (growing at both altitudes), E. angustifolim (growing at $1782 \mathrm{~m}$ a.s.l.) and $F$. vesca (growing at $1500 \mathrm{~m}$ a.s.l.) in comparison with those at the control altitude. Our data are in a good agreement with data of [18]. The authors studied the effect of altitude on the physiological characteristics of Leymus secalinus (Georgi) Tzvel. - an important forage crop on the Qinghai-Tibetan Plateau. They reported that Chl $a$ and Chl $b$ content decreased with the increase of elevation and suggested that this may be an adaptive response of $L$. secalinus to avoid oxidative damage by reducing light absorption and preventing the production of ROS. Different strategies for protection of leafs chlorophylls was observed between evergreen and woody life forms [4]. Probably the detected by us decreased contents of Chl $a$ and $\mathrm{Chl} b$ with increase of the altitude (595 $\mathrm{m}$ a.s.l., $1500 \mathrm{~m}$ a.s.l., $1782 \mathrm{~m}$ a.s.l.), could be due to different adaptive mechanisms developed by each of the plant species for avoidance of oxidative damages. On the other hand our results show lower levels of $\mathrm{Chl} b$ than the levels of $\mathrm{Chl} a$ in the five wild plant species at both Rila altitudes. This observation is in agreement with other studies [4], [18]. The authors obtained that Chl $b$ content decreased more rapidly than that of Chl $a$ in plants 
from eight altitudes of the Qinghai-Tibetan Plateau [18]. Similar response was observed in evergreen woody species [4].

Chlorophyll $a / b$ ratio is other important endpoints which give information about the effect of environmental stress factors on plants. The degree of formation of the photosynthetic apparatus was assessed by the ratio of chlorophyll $a / b$. Our data for the wild species $F$. vesca, $M$. sylvatica, $A$. millefolium, $E$. angustifolium and $D$. glomerata, growing at different altitudes in Sofia and Rila Mountain (595 m, $1500 \mathrm{~m}, 1782 \mathrm{~m}$ ) showed that there was no change in chlorophyll $a / b$ ratio. Opposite to our results are findings of [16], which reveals that chlorophyll a/b ratio in four Artemisia species was higher in the plants at $3600 \mathrm{~m}$ than those at $550 \mathrm{~m}$. Differences in chlorophyll $a / b$ ratio at same two altitudes were less in temperate species than in other species [16]. Having in mind the fact that higher chlorophyll $a / b$ ratio is related with the lower photosystem II activity and the presence of fewer depressed thylakoids, the authors suggested that the activities of photosystem II decrease due to less number of grana and this influences the dry matter production at higher altitudes [16]. Chlorophyll $a / b$ ratio was significantly increased in evergreen species at the high versus low altitude when were studied two life forms (evergreen and deciduous species) at two altitudes (1800-2400 and 2400$2800 \mathrm{~m}$ a.s.l.) from Gongga Mountain, south-west China [4]. It was suggested that both life forms have different strategies to protect leaf chlorophylls. Evergreen species tend to change the leaf pigment ratio to cope with adverse environmental stresses combined with the elevation [4].

Our results obtained for chlorophyll ratio measured in the herbaceous plants from Sofia and from both mountain altitudes are in a good agreement with data reported by [6]. The authors obtained that the values for ratio of chlorophyll $a / b$ in grasses were in close range and in the components of mixtures it was stable [6]. It has been known that environmental stresses could result to: lower levels of chlorophyll $a$ and chlorophyll $b$, chloroplast damage or halting chlorophyll synthesis. The ratio is related to the basic activity of chlorophyll $a$ and in its high values are indications of the greater intensity of photosynthesis [7]. Chlorophyll $b$ is more sensitive molecule than chlorophyll $a$ to environmental stresses. Therefore, increase of the chlorophyll $a / b$ ratio with the increase of the environmental stresses, could be a protective mechanism which could lead to reducing the damages from activated oxygen species [4]

It could be supposed that the chlorophyll $a / b$ ratio in the wild plant species used in our study has not changed with increasing the altitudes and could be considered that for genotypes of $F$. vesca, $M$. sylvatica, A. millefolium, E. angustifolium and D. glomerata, the mountain conditions are not stressful enough.

Carotenoids are a multifunctional complex with both functions. On one hand they are involved in photosynthesis and the composition of light-harvesting complexes and on the other hand they are capable of effectively removing the accumulated ROS to avoid the damage to chloroplasts caused by photooxidation [18]. We detected that the levels of total carotenoids of
F. vesca, M. sylvatica, A. millefolium, E. angustifolium and D. glomerata growing at $1500 \mathrm{~m}$ a.s.l and $1782 \mathrm{~m}$ a.s.l. were lower or similar to those at control altitude. But only for genotypes $M$. sylvatica and $A$. millefolium (growing at both Rila altitudes) were measured statistically lower levels of total carotenoids in comparison with those from the control altitude. In accordance with our results are data of [19]. The authors reported that carotenoid contents decrease at high altitudes [19]. But the data in literature for carotenoid content are contradictory. Some authors found dependence of levels of total carotenoid content on collected sites and year of the study in Melica nutans L. growing in two forest habitats in the Zielonka Forest Landscape Park in the Greater Poland region [10]. It was supposed that the enhancement in carotenoid contents with increasing of the altitude could be due to the protective function of the pigments in the dissipation of excess energy and scavenging of free radicals. Based on our data it could be speculated that probably genotypes $F$. vesca, $M$. sylvatica, A. millefolium, E. angustifolium and D. glomerata are able to overcome the combined stress in mountain conditions and react with different levels of total carotenoids. Genotypes F. vesca, E. angustifolium, D. glomerata were with similar levels of total chlorophylls while genotypes $M$. sylvatica and A. millefolium were with lower levels in comparison with the control. Species-specific dependence was found.

\section{CONCLUSION}

The results may reveal the adaptation mechanism and survival strategies of $F$. vesca, M. sylvatica, A. millefolium, E. angustifolium and D. glomerata under complex environmental stresses in both mountain altitudes by alteration of the values of chlorophylls and carotenoids. On the other hand no change in the chlorophyll $a / b$ ratio could be an indication that altitudes have no permanent damage on the leaf photochemical system of these plant species. Because of the fact that in mountain conditions the effect of altitude is combined with other abiotic factors and that pigment content is very variable depending on many factors further studies using other plant species are needed for better understanding of the mechanisms of interaction between factors and plant response.

Acknowledgements: The paper is a part of the research done within the project under contract grant number DN 04/1, entitled: "Study of the combined effects of the natural radioactive background, UV radiation, climate change and cosmic rays on model groups of plant and animal organisms in mountain ecosystems". The authors would like to thank the Bulgarian Ministry of Education, Youth and Science.

\section{REFERENCES}

1. N. Nikolova, J. Laporte, G. Tomova, "Extreme temperature months in Rila Mountain, Bulgaria (1960-2012)", Glasnik Srpskog geografskog društva, vol. 98, no. 1, pp. 49-59, 2018. https://doi.org/10.2298/GSGD180415007N 
2. R. G. Barry, Mountain weather and climate, London, UK: Methuen, 1981, 313 pages.

3. N. Kumar, S. Kumar, K. Vats, P. S. Ahuja, "Effect of altitude on the primary products of photosynthesis and the associated enzymes in barley and wheat", Photosynthesis Research, vol. 88, pp. 63-71, 2006. https://doi.org/10.1007/s11120-005-9028-6

4. Y. Li, D. Yang, S. Xiang, G. Li, "Different responses in leaf pigments and leaf mass per area to altitude between evergreen and deciduous woody species", Australian Journal of Botany, vol. 61, pp. 424-435, 2013.

https://doi.org/10.1071/BT13022

5. Y. Li et al., "Factors influencing leaf chlorophyll content in natural forests at the biome scale", Front. Ecol. Evol., vol. 6, article no. 64, 2018. https://doi.org/10.3389/fevo.2018.00064

6. V. Vasileva, A. Ilieva, "Some physiological parameters in mixtures of cocksfoot and tall fescue with subterranean clove", Bulgarian Journal of Agricultural Science, vol. 23, no. 1, pp. 71-75, 2017.

7. M. Titova, "Content of photosynthetic pigments in needles of Picea Abies and Picea koraiensis", Vestnik of taiga station of DVORAS, vol. 12, no. 118, pp. 9-12, 2010.

8. J. Nurmakova, "Photosynthetic characteristics of sorghum, soybeans and mixed crops in agroecosystems", Natural Science, vol. 2, pp. 196-201, 2013.

9. E. Smirnova, V. Reshetnikova, T. Makarova, G. Karavaeva, "Features of genotic relations in the one-specy and mixed crops of Mellilotus officinalis L." in Proceedings of the Samara scientific center of $R A S$, vol. 15, no. 3, pp. 793-795, 2013.

10. W. Zielewicz, B. Wróbel, G. Niedbała, "Quantification of chlorophyll and carotene pigments content in Mountain Melick (Melica nutans L.) in relation to edaphic variables", Forests, vol. 11, no. 11, article no. 1197, 2020.

https://doi.org/10.3390/f11111197

11. K. Rajalakshmi, N. Banu, "Extraction and estimation of chlorophyll from medicinal plants", Intern. J. Sci. Res., vol. 4, no. 11, pp. 209-212, 2015.

12. Rila National Park, Management Plan 2001-2010, Jun 2001.

Retrieved from: http://ril

anationalpark.bg/assets/userfiles/Rila\%20NP-

en.pdf

Retrieved on: May 15, 2021

13. S. P. Gateva et al., "Effect of UV radiation and other abiotic stress factors on DNA of different wild plant species grown in three successive seasons in alpine and subalpine regions." Phyton, vol. 91, no. 2, pp. 293-313, 2022.

https://doi.org/10.32604/phyton.2022.016397

14. D. I. Arnon, "Copper enzyme in isolated chloroplast polyphenol oxidase in Beta vulgaris", Plant Phys., vol. 24, no. 1, pp. 1-15, 1949.

https://doi.org/10.1104/pp.24.1.1

15. W. W. Covington, "Altitudinal variation of chlorophyll concentration and reflectance of the bark of Populus tremuloides", Ecology, vol. 56, pp. 715-720, 1975

https://doi.org/10.2307/1935507

16. S. Nautiyal, "High altitude acclimatization in Artemisia: changes in chlorophyll contents", Indian J. Plant Physiol., vol. 29, no. 1, pp. 89-94, 1986. Retrieved from:

https://www.samviti.com/img/1341/society/publica tion/ijpp-290-1-012.pdf

Retrieved on: May 15, 2021

17. P. Rajsnerová et al., "Morphological, biochemical and physiological traits of upper and lower canopy leaves of European beech tend to converge with increasing altitude", Tree Physiology, vol. 35, no. 1, pp. 47-60, 2015

https://doi.org/10.1093/treephys/tpu104

18. G. Cui et al., "Physiological analysis of the effect of altitudinal gradients on Leymus secalinus on the Qinghai-Tibetan Plateau”, PLOS ONE, vol. 13, no. 9, article no. e0202881, 2018.

https://doi.org/10.1371/journal.pone.0202881

19. K. S. Ahmad et al., "Morpho-anatomical and physiological adaptations to high altitude in some Aveneae grasses from Neelum Valley, Western Himalayan Kashmir", Acta Physiologiae Plantarum, vol. 38, no. 4, article no. 93, 2016. https://doi.org/10.1007/s11738-016-2114-x 